\title{
Respon Pertumbuhan Kelapa Sawit Bibit (Elaeis guineensis Jacq.) Terhadap Jenis fungi mikoriza arbuskula pada Dua Tingkat Pemupukan NPK
}

\section{Growth Response of Oil Palm Seedling ( Elaeis guineensis Jacq.) to Give Five Types of Arbuscular Mycorrhizal Fungi on Two Level NPK Fertilize}

\author{
Novri Dwi Damayanti ${ }^{1}$, Maria Viva Rini ${ }^{2}$, dan Rusdi Evizal ${ }^{2}$ \\ ${ }^{1}$ Mahasiswa Jurusan Agroteknologi Fakultas Pertanian Universitas Lampung \\ ${ }^{2}$ Dosen Jurusan Agroteknologi Fakultas Pertanian Universitas Lampung \\ Jln. Prof Soemantri Brodjonegoro No.1 Bandar Lampung 35143 \\ Korespondensi: damayanti.novri@yahoo.com
}

\begin{abstract}
Oil palm (Elaeis guineensis Jacq.) is one of the important excellent crop plantations which have significance for the development of national farm and country source of foreign exchange earnings. Oil palm cultivation is mostly done on the ground of ultisol that have constraints phosphorus deficiency that needed improvement in the quality of the nursery with the utilization of arbuscular mycorrhiza fungi (AMF). The study aimed: (1) determine the best type of AMF in enhancing the growth of oil palm seedlings, (2) determine dose of NPK fertilize most appropriate for the oil palm seedling, (3) determine whether the response of oil palm seedlings to type AMF influenced by dose NPK fertilizer, and (4)determine the best dose of NPK fertilizer for each type of AMF. The treatment design is a factorial (6x2) arranged in randomize completely block design with 5 replications. The first factor is the type of $A M F$, design as without AMF, Glomus sp. Isolate MV 23, Glomus sp. Isolate MV 26, Entrophospora sp. Isolate MV 22, Entrophospora sp. Isolate MV 25, Entrophospora sp. Isolate MV 28.The second factor is number of NPK fertilize design as $p_{1}$ (100\% from recomendation) and $p_{2}$ (50 $\%$ from recomendation). Means homogeneity among the treatments were tested using Barlett test and the aditivity data were tested with Tukey test. Separation of means value were analyzed using Least Significant Difference (LSD) at 5\% significance level. The results showed the interaction between the type and dose of NPK fertilizer AMF is can be concluded that (1) oil palm seedlings response to AMF inoculation type is determined by the dose of NPK fertilizer on the variable plant height, dry weight of root, and number of primary roots, 2) the optimum dose for each type of AMF are used based on the data root dry weight is a combination of $100 \%$ NPK fertilizer with each type of AMF, excepton the AMF types Entrophospora sp. Isolates MV 22.
\end{abstract}

Keywords: Growth Response, Oil Palm Seedling, Arbuscular Mycorrhizal 


\section{PENDAHULUAN}

Kelapa sawit (Elaeis guineensis Jacq.) merupakan salah satu primadona tanaman perkebunan yang memiliki prospek pengembangan cukup cerah (Fauzi et al., 2012). Indonesia memiliki luas areal kelapa sawit terbesar di dunia, yaitu sebesar 34,18 \% dari luas kelapa sawit dunia (Fauzi et al., 2012). Pada tahun 2012, luas perkebunan kelapa sawit di Indonesia mencapai \pm 9.074 .621 ha dan total produksi \pm 23.521 .071 ton TBS (tandan buah segar). Di Provinsi Lampung sampai tahun 2012, luas perkebunan kelapa sawit mencapai \pm 153.160 ha dan total produksi \pm 401.952 ton TBS dengan sebagian besar jenis tanah di Lampung adalah Podsolik Merah Kuning (PMK) seluas 1.522.336 ha (Direktorat Jenderal Perkebunan, 2012).

Dalam sistem klasifikasi tanah USDA, tanah PMK secara umum tergolong dalam ordo Ultisol. Menurut Notohadiprawiro (2006) yang dikutip oleh Madjid (2009), pada umumnya lahan kering masam didominasi oleh tanah ultisol yang dicirikan oleh kapasitas tukar kation (KTK) dan kemampuan memegang atau menyimpan air yang rendah, tetapi kadar Al tinggi sehingga sebagian besar fosfat dalam keadaan tersemat oleh $\mathrm{Al}$ dan $\mathrm{Fe}$, tidak tersedia bagi tanaman maupun biota tanah. Untuk mengatasi permasalahan budidaya tanaman kelapa sawit pada tanah ultisol diperlukan pengembangan teknologi yang dilakukan dengan perbaikan mutu tanaman di pembibitan. Salah satunya adalah dengan pemanfaatan mikroorganisme tanah berupa fungi mikoriza yang dapat bekerja sama dengan akar tanaman dalam menyerap unsur hara dan air.

Mikoriza merupakan suatu bentuk asoasiasi mutualisme antara fungi (myces) dan perakaran (rhiza) tumbuhan tingkat tinggi. Berdasarkan struktur tubuhnya dan cara infeksi terhadap tanaman inang, mikoriza dapat dikelompokkan ke dalam 3 golongan besar yaitu Endomikoriza, Ektomikoriza, dan Ektendomikoriza (Kabirun dan Widada, 1994). Fungi yang tergabung ke dalam endomikoriza banyak mendapat perhatian karena penyebarannya lebih luas dan dapat berasosiasi dengan hampir 90\% spesies tanaman tingkat tinggi, salah satunya FMA (Cruz, Ishii, dan Kadoya, 2000). Fungi mikoriza dan akar hidup secara simbiosis mutualis, saling memberikan manfaat. Fungi memperoleh pasokan karbon dan energi dari akar dan selanjutnya fungi membantu akar dalam penyerapan unsur hara bagi tanaman, terutama unsur-unsur hara yang jumlahnya sedikit di dalam tanah dan tidak mobil, seperti P, dan meningkatkan serapan air dan ketahanan terhadap kekeringan (Munawar, 2010). Terdapat beberapa faktor yang mempengaruhi perkembangan FMA. Keefektifan setiap jenis FMA dipengaruhi oleh jenis tanaman dan jenis tanah (Daniels dan Menge, 1981 yang dikutip oleh Kartika, 2012). Selain itu juga, aktivitas dan perkembangan fungi mikoriza sangat dipengaruhi oleh tingkat pemupukan fosfat (White, 1989 yang dikutip Zulaikha dan Gunawan 2006).

Penelitian ini bertujuan untuk menentukan jenis FMA terbaik dalam meningkatkan pertumbuhan bibit kelapa sawit, menentukan dosis pupuk NPK yang paling sesuai untuk bibit kelapa sawit, mengetahui apakah respons bibit kelapa sawit terhadap jenis FMA dipengaruhi oleh dosis pupuk NPK, menentukan dosis pupuk NPK terbaik untuk masing-masing jenis FMA.

\section{METODE}

Penelitian dilaksanakan di Laboratorium Produksi Perkebunan, rumah kaca Fakultas Pertanian Universitas Lampung, dan lahan Politeknik Negeri Lampung dari bulan Mei 2013 sampai Maret 2014. Peralatan yang digunakan antara lain mikroskop stereo dan majemuk, kaca preparat, cawan petri, pinset spora, timbangan elektrik, oven listrik, dan saringan mikro (ukuran 500, 63 dan $45 \mu \mathrm{m}$ ). Bahan- 
bahan yang digunakan antara lain benih kelapa sawit (D x P) Simalungun, mikoriza Glomus sp. (Isolat MV 23 dan Isolat MV 26) Entrophospora sp. (Isolat MV 22, Isolat MV 25, dan Isolat MV 28), pupuk "Rock Phospate", pupuk Urea, pupuk NPK, larutan KOH $10 \%$, HCL 1\%, glycerol, dan trypan blue.

Percobaan ini menggunakan rancangan faktorial $(6 \times 2)$ dengan 5 ulangan. Faktor pertama yaitu jenis mikoriza (I) yang terdiri dari 6 jenis yaitu tanpa inokulasi mikoriza ( $\left.\mathrm{i}_{0}\right)$, Glomus sp. Isolat MV $23\left(\mathrm{i}_{1}\right)$, Glomus sp. Isolat MV $26\left(\mathrm{i}_{2}\right)$, Entrophospora sp. Isolat MV $22\left(\mathrm{i}_{3}\right)$, Entrophospora sp. Isolat MV $25\left(\mathrm{i}_{4}\right)$, Entrophospora sp. Isolat MV $28\left(\mathrm{i}_{5}\right)$. Adapun deskripsi masing-masing isolat yang digunakan dapat dilihat pada Tabel 1. Faktor kedua yaitu pemberian pupuk NPK (P) yang terdiri dari 2

Tabel 1. Jenis isolat yang digunakan dalam penelitian

\begin{tabular}{lll}
\hline \multicolumn{1}{c}{ Jenis } & \multicolumn{1}{c}{ Asal } & \multicolumn{1}{c}{ Tanaman inang } \\
\hline Glomus sp. (Isolat MV 23) & Gunung Para, Sumatera Utara & Kelapa sawit \\
Glomus sp.(Isolat MV 26) & Notonegoro, Jember Jawa Timur & Jarak pagar \\
Entrophospora sp. (Isolat MV 22) & Sekampung Udik, Lampung & Kelapa sawit \\
Entrophospora sp.(Isolat MV 25) & Bentar Kersik B, Sumatera Utara & Kelapa sawit \\
Entrophospora sp.(Isolat MV 28) & Sendang Anom, Lampung & Kelapa sawit \\
\hline
\end{tabular}

Taraf yaitu $100 \%$ dosis anjuran NPK/polibag $\left(\mathrm{p}_{1}\right)$ dan $50 \%$ dosis anjuran NPK/polibag $\left(\mathrm{p}_{2}\right)$

Perlakuan diterapkan pada satuan percobaan di pre-nursery dan main nursery dalam rancangan kelompok teracak sempurna (RKTS) Kesamaan ragam antar perlakuan diuji dengan Uji Barlett dan kemenambahan data diuji dengan uji Tukey. Jika asumsi terpenuhi, data dianalisis ragam dan dilanjutkan uji Beda Nyata Terkecil (BNT) pada taraf nyata 5\%.

\section{Penyemaian benih}

Benih kelapa sawit yang telah berkecambah disemai pada media pasir yang telah disterilkan sampai umur 4 minggu sebelum dipindahkan ke pre-nursery.

\section{Penanaman di pre-nursery dan inokulasi spora FMA}

Benih kelapa sawit yang telah dikecambahkan selama 4 minggu dipindahkan ke polibag berukuran $18 \times 25 \mathrm{~cm}$ (satu bibit per polibag) dengan media tanam tanah yang tidak steril dan bahan organik (7:1) kemudian media ditambahkan pupuk Rock Phosphate sebanyak 100 gr untuk 60 polybag pre-nursery. Proses inokulasi FMA sesuai perlakuan diawali dengan mengeluarkan bibit dari media semaian. Inokulum FMA (dengan carrier zeolit dan pasir) kepadatan spora \pm 500 spora/bibit ditaburkan merata pada akar yang terletak di atas lubang tanam. Setelah bibit berumur 4 minggu di pre-nursery, dilakukan pemupukan urea dengan dosis 2 g per liter untuk 100 bibit dengan cara disemprotkan pada daun setiap minggu.

\section{Penanaman di main nursery}

Transplanting bibit dari pre-nursery ke main nursery dilakukan setelah bibit berumur 3 bulan dengan memindahkan bibit ke polibag berukuran $40 \times 50 \mathrm{~cm}$ dengan media tanam tanah top soil yang tidak steril. Penanaman bibit diawali dengan membuat lubang tanam pada media yang ada di polibag main nursery dengan menggunakan alat ponjo. 


\section{Pemeliharaan tanaman}

Adapun pemeliharaan yang dilakukan selama penelitian antara lain penyiraman, penyiangan gulma, pengendalian hama dan penyakit, serta pemupukan. Jenis dan dosis pupuk yang digunakan pada penelitian ini disesuaikan dengan pertumbuhan bibit dan perlakuan yang digunakan (Tabel 2).

Tabel 2. Jenis dan dosis pupuk yang digunakan dalam penelitian

\begin{tabular}{ccccccccccc}
\hline N:P:K (15:15:15) & \multicolumn{10}{c}{ Umur tanaman (minggu) } \\
\cline { 2 - 12 } (g/polibag) & $14-15$ & $16-17$ & $18-20$ & $22-24$ & 26 & 28 & 30 & 32 & 34 & 36 \\
\hline $100 \%$ & $2,5 \mathrm{~g}$ & $5 \mathrm{~g}$ & $7,5 \mathrm{~g}$ & $10 \mathrm{~g}$ & $10 \mathrm{~g}$ & $10 \mathrm{~g}$ & $10 \mathrm{~g}$ & $10 \mathrm{~g}$ & $15 \mathrm{~g}$ & $15 \mathrm{~g}$ \\
$50 \%$ & $1,25 \mathrm{~g}$ & $2,5 \mathrm{~g}$ & $3,75 \mathrm{~g}$ & $5 \mathrm{~g}$ & $5 \mathrm{~g}$ & $5 \mathrm{~g}$ & $5 \mathrm{~g}$ & $5 \mathrm{~g}$ & $7,5 \mathrm{~g}$ & $7,5 \mathrm{~g}$ \\
\hline
\end{tabular}

\section{Variabel pengamatan}

Pengamatan dilakukan setelah bibit berumur 36 minggu setelah semai. Untuk menguji kesahihan kerangka pemikiran dan hipotesis dilakukan pengamatan terhadap variabel-variabel tinggi tanaman, jumlah daun, tingkat kehijauan daun, bobot segar tajuk, bobot kering tajuk, bobot segar akar, bobot kering akar, jumlah akar primer, volume akar, persen infeksi akar dan jumlah spora.

\section{HASIL DAN PEMBAHASAN}

Hasil penelitian menunjukkan bahwa perlakuan FMA berpengaruh nyata pada pengamatan jumlah akar primer, persen infeksi, dan jumlah spora. Sedangkan perlakuan dosis pupuk NPK berpengaruh pada pengamatan tinggi tanaman, bobot segar tajuk, bobot kering tajuk, dan persen infeksi akar. Pada variabel tinggi tanaman, bobot kering akar, dan jumlah akar primer respon bibit kelapa sawit terhadap pemberian FMA dipengaruhi oleh dosis pupuk NPK (Tabel 3).

Tabel 3.Rekapitulasi analisis ragam data penelitian.

\begin{tabular}{lccc}
\hline \multirow{2}{*}{ Variabel Pengamatan } & & Perlakuan & \\
\cline { 2 - 4 } & FMA $(\mathrm{M})$ & Pupuk $(\mathrm{P})$ & $\mathrm{M} \times \mathrm{P}$ \\
\hline Tinggi tanaman & tn & $*$ & $*$ \\
Jumlah daun & tn & tn & tn \\
Tingkat kehijauan daun & tn & $*$ & tn \\
Bobot segar tajuk & tn & $*$ & tn \\
Bobot kering tajuk & tn & tn & tn \\
Bobot segar akar & tn & tn & tn \\
Bobot kering akar & $*$ & tn & $*$ \\
Jumlah akar primer & tn & tn & tn \\
Volume akar & $*$ & $*$ & tn \\
Persen infeksi akar & $*$ & tn & tn \\
Jumlah spora & & &
\end{tabular}

\section{Keterangan:}

$$
\begin{array}{ll}
\text { tn } & =\text { tidak nyata pada } \alpha=5 \% \\
* & =\text { nyata pada } \alpha=5 \%
\end{array}
$$

FMA dapat berasosiasi dengan hampir $90 \%$ jenis tanaman. Tiap jenis tanaman juga dapat berasosiasi dengan satu atau lebih jenis FMA. Walaupun demikian, hal penting yang perlu diperhatikan dalam pemanfaatan FMA untuk bibit tanaman adalah, bahwa tidak semua jenis tanaman 
Novri Dwi Damayanti dkk: Respon Pertumbuhan Kelapa Sawit Bibit (Elaeis guineensis Jacq.) Terhadap ....

dapat memberikan respon pertumbuhan positif terhadap inokulasi FMA, hal ini sangat tergantung dari tingkat "mycorrhizal dependency" dari tanaman tersebut (Setiadi, 2012).

Hasil penelitian menunjukkan bahwa respons tanaman terhadap dosis pupuk NPK ditentukan oleh perlakuan FMA pada peubah tinggi (Tabel 4). Kombinasi terbaik pada pemberian dosis pupuk NPK 100\% dari dosis anjuran dengan perlakuan FMA jenis Entrophospora sp. Isolat MV 28, namun tidak berbeda nyata dengan inokulasi FMA jenis Glomus sp. IsolatMV 26 dan tanpa mikoriza. Sedangkan pada pemberian dosis pupuk NPK50 \% dari dosis anjuran dengan perlakuan FMA jenis Entrophospora sp. Isolat MV 22 menghasilkan tinggi tanaman lebih tinggi dibandingkan tanpa mikoriza.

Tabel 4.Kombinasi perlakuan jenis FMA dan dosis pupuk NPK pada tinggi tanaman bibit kelapa sawit umur 9 bulan.

\begin{tabular}{|c|c|c|}
\hline \multirow{2}{*}{ Inokulasi } & \multicolumn{2}{|c|}{ dosis pupuk } \\
\hline & $100 \%$ & $50 \%$ \\
\hline & & \\
\hline Tanpa Mikoriza & $94,3(\mathrm{a}) \mathrm{ab}$ & 78,44 (b)e \\
\hline Glomus sp. IsolatMV 23 & 85,52 (a)cde & 85,48 (a)cde \\
\hline Glomus sp. Isolat MV 26 & $94,98(a) a b$ & 89,94 (a)abcd \\
\hline Entrophospora sp. Isolat MV 22 & 84,20 (b)de & 93,88 (a)abc \\
\hline Entrophospora sp. Isolat MV 25 & 87,94 (a)bcd & 82,20 (a)de \\
\hline Entrophospora sp. Isolat MV 28 & 96,68 (a)a & 83,32 (b)de \\
\hline BNT $5 \%$ & 8,76 & \\
\hline
\end{tabular}

Keterangan: Nilai tengah yang diikuti dengan huruf yang sama pada arah horizontal (dalam tanda kurung) atau verikal (tanpa tanda kurung) tidak berbeda menurut uji BNT pada $\alpha 5 \%$.

Pada variabel pengamatan jumlah daun bibit kelapa sawit,perlakuan inokulasi FMA jenis Glomus sp. Isolat MV 23 memiliki jumlah daun yang lebih banyak dibandingkan dengan perlakuan tanpa mikoriza dan perlakuan FMA jenis Entrophospora sp. Isolat MV 25. Sedangkan pada variabel pengamatan tingkat kehijauan daun perlakuan FMA tidak berpengaruh nyata.Pemberian dosis pupuk NPK tidak berpengaruh nyata pada jumlah daun dan tingkat kehijauan daun bibit kelapa sawit.(Tabel $5)$.

Tabel 5.Pengaruh perlakuan FMA dan dosis pupuk NPK pada jumlah daun dan tingkat kehijauan daun bibit kelapa sawit umur 9 bulan.

\begin{tabular}{lcc}
\hline Perlakuan & Jumlah daun & Tingkat kehijauan daun \\
\hline & ----- Helai ----- & $60,29 \mathrm{a}$ \\
Tanpa Mikoriza & $11,30 \mathrm{~b}$ & $58,81 \mathrm{a}$ \\
Glomus sp. Isolat MV 23 & $12,30 \mathrm{a}$ & $62,07 \mathrm{a}$ \\
Glomus sp. Isolat MV 26 & $11,70 \mathrm{ab}$ & $60,93 \mathrm{a}$ \\
Entrophospora sp. Isolat MV 22 & $12,00 \mathrm{ab}$ & $59,57 \mathrm{a}$ \\
Entrophospora sp. Isolat MV 25 & $11,40 \mathrm{~b}$ & $58,15 \mathrm{a}$ \\
Entrophospora sp. Isolat MV 28 & $11,85 \mathrm{ab}$ & 4,89 \\
\hline BNT 5 \% & 0,86 & $59,89 \mathrm{a}$ \\
\hline NPK 100\% dosis anjuran & $11,72 \mathrm{a}$ & $60,05 \mathrm{a}$ \\
\hline NPK 50\% dosis anjuran & $11,80 \mathrm{a}$ & 2,83 \\
\hline BNT 5\% & 0,49 & $\mathrm{~B}$
\end{tabular}


Hasil penelitian menunjukkan bahwa perlakuan FMA tidak berpengaruh nyata terhadap bobot segar dan bobot kering tajuk, tetapi sebaliknya perlakuan dosis pupuk NPK mempengaruhi bobot segar dan bobot kering tajuk. Bobot segar dan bobot kering tajuk lebih tinggi diperoleh pada tanaman yang di pupuk NPK $100 \%$ dari dosis anjuran (Tabel 6). Menurut Wachjar et al. (1998) yang dikutip oleh Hadi (2011), pemupukan N memberikan pengaruh terhadap nisbah bobot kering tajuk-akar.Hal ini karena nitrogen merupakan komponen penyusun auksin indole-3 acetic acid (IAA) dan sitokinin. Dengan tingginya konsentrasi auksin akan meningkatkan akumulasi pada bobot kering tajuk.

Tabel 6. Pengaruh perlakuan FMA dan dosis pupuk NPK pada bobot segar, bobot kering tajuk, bobot segar akar dan volume akar bibit kelapa sawit umur 9 bulan.

\begin{tabular}{lcccc}
\hline Perlakuan & $\begin{array}{c}\text { bobot segar } \\
\text { tajuk }\end{array}$ & $\begin{array}{c}\text { bobot kering } \\
\text { tajuk }\end{array}$ & $\begin{array}{c}\text { Bobot segar } \\
\text { akar }\end{array}$ & Volume akar \\
\hline Tanpa Mikoriza & $-------\mathrm{g}------$ & $------\mathrm{g}-----$ & $------\mathrm{g} \mathrm{-------}$ & $------\mathrm{ml} \mathrm{-----}$ \\
Glomus sp. Isolat MV 23 & $367,07 \mathrm{a}$ & $88,70 \mathrm{a}$ & $96,89 \mathrm{a}$ & $134,00 \mathrm{~b}$ \\
Glomus sp. Isolat MV 26 & $332,32 \mathrm{a}$ & $84,38 \mathrm{a}$ & $93,05 \mathrm{a}$ & $149,00 \mathrm{ab}$ \\
Entrophospora sp. Isolat MV 22 & $387,41 \mathrm{a}$ & $92,64 \mathrm{a}$ & $102,06 \mathrm{a}$ & $153,00 \mathrm{ab}$ \\
Entrophospora sp. Isolat MV 25 & $371,84 \mathrm{a}$ & $92,42 \mathrm{a}$ & $97,35 \mathrm{a}$ & $149,00 \mathrm{ab}$ \\
Entrophospora sp. Isolat MV 28 & $343,90 \mathrm{a}$ & $83,32 \mathrm{a}$ & $94,00 \mathrm{a}$ & $145,00 \mathrm{ab}$ \\
\hline BNT 5\% & $366,96 \mathrm{a}$ & $91,31 \mathrm{a}$ & $102,98 \mathrm{a}$ & $161,75 \mathrm{a}$ \\
\hline NPK 100 \% dosis anjuran & 79,21 & 20,27 & 16,39 & 23,28 \\
NPK 50\% dosis anjuran & $388,06 \mathrm{a}$ & $95,25 \mathrm{a}$ & $101,89 \mathrm{a}$ & $154,25 \mathrm{a}$ \\
\hline BNT 5\% & $335,11 \mathrm{~b}$ & $82,34 \mathrm{~b}$ & $93,55 \mathrm{a}$ & $143,00 \mathrm{a}$ \\
\hline Keterangan Dua & 45,73 & 11,70 & 9,46 & 13,44 \\
\hline
\end{tabular}

Keterangan: Dua nilai tengah yang diikuti dengan huruf yang sama tidak berbeda menurut uji BNT pada $\alpha 5 \%$

Perlakuan inokulasi FMA Entrophospora sp. Isolat MV 28 memiliki volume akar yang tertinggi, namun tidak berbeda nyata dengan inokulasi FMA lainnya. Sedangkan, perlakuan tanpa mikoriza menghasilkan volume akar terendah berbeda nyata dengan inokulasi FMA Entrophospora sp. Isolat MV 28 (Tabel 6). Menurut Widiastuti (2002), arsitektur perakaran bibit kelapa sawit yang diinokulasi FMA lebih baik dibandingkan dengan bibit yang tidakdiinokulasi FMA. Peningkatan sistem perakaran merupakan salah satu mekanisme bibit kelapa sawit bermikoriza dalam meningkatkan serapan $\mathrm{P}$ dan pertumbuhan tanaman.

Setelah dilakukan penghitungan jumlah spora FMA indigenus pada media tanah adalah 13 spora/100 gram tanah. Pada penelitian ini menggunakan media tanah sebanyak $20 \mathrm{~kg}$, sehingga populasi spora yaitu 2600 spora indegenus pada setiap perlakuan (kontrol) tanpa inokulasi FMA. Pada pengamatan jumlah spora memperjelas pengamatan persen infeksi yang menunjukkan bahwa jenis FMA berpengaruh positif pada infeksi akar. Persen infeksi akar pada perlakuan inokulasi FMA berkisar 45,76\% sampai 54,05\%. Semua jenis FMA baik Glomus sp. maupun Entrophospora sp. yang diujikan memperlihatkan persen infeksi yang baik. Hal ini diduga karena tanaman kelapa sawit merupakan tanaman inang yang cocok untuk berkembangnya berbagai jenis FMA baik Glomus sp. maupun Entrophospora sp., termasuk pada tanaman kontrol (tidak diinokulasi FMA) infeksi akar cukup tinggi yaitu sebesar 35,70\%. Adanya infeksi FMA pada akar bibit kontrol karena tidak dilakukan proses sterlisasi media sehingga kelapa sawit terinfeksi oleh FMA indegenus yang berasal dari media tanah. Menurut Daniels dan Trappe yang dikutip oleh Suhardi (1988), spora Glomus epigaeum gagal berkecambah pada tanah yang disterilkan dengan menggunakan autoclaf, dipanaskan dengan uap, diinokulasi radiasi sinar gamma, sebaliknya perkecambahan yang tinggi terdapat pada tanah-tanah yang nonsteril.

Menurut Allen (2001), keterpaduan antar inang dengan FMA dapat dilihat dengan derajat infeksi akar inangnya walaupun belum tentu menggambarkan tinggi rendahnya pertumbuhan dan 
produksi tanaman inang. Oleh karena itu peubah derajat infeksi akar tanaman inang digunakan hanya untuk mengindikasikan adanya simbiosis antara FMA dengan inang.

Namun berdasarkan data yang diperoleh, secara umum pertumbuhan tanaman (kontrol) tanpa inokulasi FMA juga dapat menghasilkan pertumbuhan yang sama baiknya dan tidak berbeda nyata dengan tanaman yang diinokulasikan FMA. Hal ini dapat disebabkan karena tidak dilakukannya proses sterilisasi media tanah sehingga terjadi infeksi FMA indigenus pada media tanah. Menurut Suhardi (1988), indigenus FMA ternyata lebih efisien di dalam meningkatkan pertumbuhan tanaman di dalam tanah karena fungi tersebut ternyata sudah lebih beradaptasi terhadap kondisi lingkungannya dibandingkan FMA lain yang baru diintroduksikan.

Pada penelitian ini didapat fakta bahwa kombinasi antara perlakuan jenis FMA dan dosis pupuk NPK hanya pada variabel pengamatan tinggi tanaman, bobot kering akar, dan jumlah akar primer (Tabel 4, 7, 8). Oleh karena itu, pada penelitian ini dapat disimpulkan bahwa dosis pupuk NPK yang sesuai untuk masing-masing jenis FMA berdasarkan peubah bobot kering akar. Dosis pupuk NPK 100\% sesuai dosis anjuran merupakan dosis yang sesuai untuk masing-masing jenis FMA kecuali pada FMA jenis Entrophospora sp. Isolat MV 22 yang lebih sesuai pada pemberian dosis pupuk NPK 50\% dari dosis anjuran. Hasil penelitian Widiastuti et al. (2002) menunjukkan bibit kelapa sawit pada perlakuan tanpa inokulasi, serapan P maksimum dicapai dengan pemupukan $100 \%$ sedangkan dengan inokulasi FMA dosis pupuk dapat dikurangi sebesar 25-50\%. Hal ini dikarenakan efisiensi serapan hara terutama $\mathrm{P}$ tanaman bermikoriza lebih baik.

\section{KESIMPULAN}

Hasil penelitian menunjukkan terjadi interaksi antara jenis FMA dan dosis pupuk NPK yang digunakan sehingga dapat disimpulkan (1) respon bibit kelapa sawit terhadap inokulasi jenis FMA ditentukan oleh dosis pupuk NPK hanya pada tinggi tanaman, bobot kering akar, dan jumlah akar primer, (2) dosis optimum untuk masing-masing jenis FMA yang digunakan berdasarkan data bobot kering akar adalah kombinasi dosis pupuk NPK $100 \%$ dengan masing-masing jenis FMA, kecuali pada FMA jenis Entrophospora sp. Isolat MV 22.

\section{SARAN}

Berdasarkan penelitian yang telah dilakukan perlu dilakukan pengujian ulang dengan menggunakan varietas kelapa sawit yang berbeda dan perlakuan tanpa pemupukan pupuk NPK pada bibit kelapa sawit untuk mengetahui pengaruh jenis FMA yang lebih nyata dibandingkan tanpa inokulasi pada bibit kelapa sawit.

\section{DAFTAR PUSTAKA}

Allen, M. F. 2001. Modeling Arbuscular Mycorrhizal Infection: is \% Infection an Appropriate Variable Mycorrhiza J. 10: 255-258. 
Cruz, A. F., T. Ishii., and K. Kadoya. 2000. Effect of Arbuscular Mycorrhizal Fungi on Tree Owth, Leaf Water Potential, and Levels of 1Aminocyclopropane-1-Carboxylic Acid and Ethylene in The Roots of Papaya Under Water-Stress Conditions. Mycorrhiza J. 10: 121-123.

Direktorat Jenderal Perkebunan. 2012. Tabel Produksi, Luas Areal dan Produktivitas Perkebunan di Indonesia. Direktorat Jenderal Perkebunan. Jakarta.

Fauzi, Y., Y. E Widyastuti., I. Satyawibawa, dan R. H. Paeru.2012. Kelapa Sawit . Penebar Swadaya. Jakarta. $236 \mathrm{hlm}$.

Hadi, A. M. 2011. Pengaruh Pemberian Glomus sp. Isolat Gigaspora sp. Isolat Entrophospora sp. Isolat dan Dua Dosis NPK pada Pertumbuhan Bibit Kelapa Sawit (Elaeis guineensis Jacq.).di Pembibitan. Skripsi Fakultas Pertanian Universitas Lampung. Bandar Lampung. 65 hlm.

Kabirun, S. dan J. Widada. 1994. Response of Soybean own on Acid Soil to Inoculation of VesicularArbuscular Mycorrhizal Fungi. Biotrop Spec. Publ. 56: 131-137.

Kartika, E. 2012. Isolasi, Karakterisasi dan Pengujian Keefektifan Fungi Mikoriza Arbuskular Terhadap Bibit Kelapa Sawit pada Tanah Gambut Bekas Hutan.Jurnal Agronomi. 10(2): 63-70.

Madjid, A. 2009. Pengelolaan Kesuburan Tanah Mineral Masam untuk Pertanian.Makalah Pengelolaan Kesuburan Tanah, Program Studi Ilmu Tanaman, Program Magister (S2), Program Pascasarjana, Universitas Sriwijaya. Palembang.

Munawar, A. 2010.Kesuburan Tanah dan Nutrisi Tanaman.IPB Press. Bogor. 240 hlm.

Suhardi. 1988. Pedoman Kuliah Mikoriza Vesikular Arbuskular (MVA). Proyek Peningkatan Perguruan Tinggi Universitas Gadjah Mada. PAU- Bioteknologi Universitas Gadjah Mada. 178 hlm.

Setiadi. 2012. Mengenal Fungsi Mikoriza sebagai Penyokong Kehidupan Tanaman Pada Lahan Lahan Marginal. Post Mining Restoration Technical Notes. Bogor.

Widiastuti, H., G. Edi, S. Nampiah, K.D. Latifah, H.D. Didiek dan S. Sally. 2002. Optimalisasi Simbiosis Cendawan Mikoriza Arbuskula Acaulospora tuberculata dan Gigaspora margarita Pada Bibit Kelapa Sawit di Tanah Masam. Menara Perkebunan. 70 (2): 50-57.

Zulaikha, S dan Gunawan.2006. Serapan Fosfat dan Respons Fisiologis Tanaman Cabai Merah Cultivar Hot Beauty terhadap Mikoriza dan Pupuk Fosfat pada tanah Ultisol.Bioscientiae. 3(2): 83-92. 